\title{
Hate rhetoric vs trust rhetoric in contemporary public discourse
}

\author{
Ekaterina Koval ${ }^{1,}$, Andrey Sychev ${ }^{2}$, and Natalya Zhadunova ${ }^{2}$ \\ ${ }^{1}$ Middle-Volga Institute (branch) of Russian State University of Justice, 430003, Saransk, Russia \\ ${ }^{2}$ Mordovian State University named after N.P. Ogarev, 6430005, Saransk, Russia
}

\begin{abstract}
Modern public discourse is so closely related to power that we can talk about the power of discourse. The value-normative basis of public discourse in most modern societies is human rights and fundamental freedoms. This leads to a high level of not only discursive diversity, but also communicative aggression, one of the most dangerous manifestations of which is the rhetoric of hatred. Although hatred rhetoric in certain communicative contexts and situations can perform useful functions based on violence, it hinders the achievement of such ideals of public discourse as the public good and justice. For this reason, in most states, the use of hate speech in public discourse is prohibited or restricted. However, the state, as a rule, finds itself in a difficult situation of a compromise between freedom of speech and social equality. On the one hand, it should ensure freedom of speech, especially in political debate; on the other hand, the state has a duty to protect discriminated and stigmatized groups. It is extremely difficult to find such a compromise using exclusively legal mechanisms, therefore, other strategies are required to squeeze out the rhetoric of hatred from public space. One of these strategies is the expanded reproduction of social trust, the accumulation of social capital, entailing a natural transition from the rhetoric of hatred to the rhetoric of trust. It is hardly possible to make such a transition without conflict, therefore, the use of compromise and consensus mechanisms is required (compromise is preferable).
\end{abstract}

\section{Introduction}

Public discourse is a way of constructing a social world. Unlike non-public, public discourse is a text that is spoken out loud. Even if he speaks in a "narrow circle", nevertheless, it has a public nature. If we are talking about the internal pronunciation of a text, about the inner world of the individual, about the worldview, these phenomena belong to non-public discourse. Non-public and public discourses have different value-regulatory grounds.

Public discourse is so closely associated with power that one can speak of the peculiar power of discourse. The one who manages the public discourse is the one who rules the society. Both social reality and the social imaginary largely depend on the content and

\footnotetext{
* Corresponding author: nwifesc78@gmail.com
} 
value-normative foundations of the discourse. As Y. V. Klyuyev notes, "A person immersed in public discourse (and speaking, and listening, and overhearing, and hearing from someone) is "captured" by the text spoken aloud" [1, p. 332].

An analysis of the historical changes in public discourse allows us to record changes in what is possible and what cannot be said. For example, in a religious society one cannot blaspheme, in a democratic society one cannot call for a totalitarian system, etc. Modern public discourse is distinguished by a variety of content and a high level of aggression. Whatever we start talking out loud, publicly, we almost inevitably encounter hate speech. It is difficult to find a public discussion about politics, the situation in society of sexual or ethnic minorities, the activities of religious organizations, the economic situation, public health, computer games, in which forms of hate expression would not be used.

In addition, it is precisely in modern public discourse that the conflict of freedom of speech and the need to restrict public statements of discriminatory or stigmatizing content is sharper than ever. P. Guerin [2] defines public discourse as the main element of the concept of human rights. In this sense, public discourse is teleological. Its goal is the public good. However, the achievement of the public good in the context of value-normative pluralism is extremely difficult. It is difficult to imagine a modern society without freedom of speech. But it can hardly be interpreted as a public good providing the opportunity to use public space to promote the ideology of violence. If the basic value of modern public discourse is human rights, the discourse must inevitably be limited in order to protect the very idea of human rights, as well as the subjects of these rights. This article focuses on the limitations of such an element of modern public discourse as hate speech.

J. Habermas [3] specifies the public space: it does not merge with either the state or the market, but it is a field for speaking and constructing social events. The main constructive force in the public sphere is the power of a better argument. However, the best argument is paradoxically strong only when it is not based on violence. M. Sellers emphasizes that "specific forms of ignorance, such as rudeness (simply reckless attitude towards others), complacency (ideologically supported reckless attitude towards others) and chauvinism (ideologically supported hostility towards others) violate the basic premise of public discourse that serves 'public good', defined as the common interest of all members of society" [4, p. 62].

The rhetoric of hatred, which may include rudeness, complacency, and especially chauvinism, is a significant obstacle to the realization of such ideals of public discourse as the public good and justice. Today, the axiological modality of hate rhetoric is practically not problematic. Despite the fact that this phenomenon may have constructive functions, there is an urgent need to identify normative regulators that allow restricting the use of hatred rhetoric in the public space, as well as describing the regulatory foundations of alternative rhetoric, which can conditionally be called "rhetoric of trust".

\section{Hate rhetoric: functions and dysfunctions}

Hate rhetoric is such an expression means of that often arise as a response to the Other's refusal to conform to any value-normative model or stereotype that has developed among subjects using hate rhetoric in public discourse. Moreover, the motives of such subjects can be very diverse: from political commitment to group resentment and individual resentment.

Related phenomena of hate speech are trolling, insult, cyberbullying, hating, shaming, stigmatization, discrimination.

The objects of hate rhetoric may not correspond to the idea of the norm on such grounds as race, nationality, religion, gender, age, country of origin, political beliefs, appearance, illness and several others. 
Despite the seemingly obvious negative axiological modality of hate rhetoric, one can speak not only about the dysfunction of this phenomenon, but also about positive functions.

For example, in conditions of military invasion, there is an urgent need for the consolidation of society, raising the morale of the population, which should repel the enemy. In this case, the rhetoric of hatred will be necessary to formulate an extremely negative attitude towards the aggressor.

Another example of the hate rhetoric functionality is the sublimation of aggression. If participants in public discourse use hate speech to prevent real violence, this is generally positive. Hate rhetoric can also serve as a way to stabilize the situation in times of crisis.

However, the rhetoric of hatred is an unreliable basis for unity; its public use is fraught with negative, hard-to-predict consequences. However, the harmful effects of the hate rhetoric use in public discourse alone cannot serve as a reliable argument in favor of its prohibition [5]. This is due, in particular, to the fact that the border between the means of expression, which are protected by freedom of speech and which violate the rights of others, is extremely blurred.

This situation significantly complicates the activities of government bodies, which have to make difficult decisions of a legislative nature, setting legal restrictions on the use of hate speech in public discourse and, which is much more difficult, defining criteria for what is related to hate speech and what is an acceptable way of public opinion expression. It should be noted that in different regions the question of the boundaries between freedom of speech and the rhetoric of hatred is solved differently. The European Court of Human Rights (ECHR), for example, formulated a position according to which hate speech is a non-normative phenomenon, however, if a person using hate speech does not violate the fundamental values declared in the European Convention for the Protection of Human Rights, then its act can be interpreted as being consistent with law, even if this will require a trial.

Obviously, the legal restrictions of hate rhetoric are not enough, given that such rhetoric is harmful in itself, regardless of whether its public use has other harmful consequences or not [6]. In addition, any attempts to limit the rhetoric of hatred, especially when it comes to the political segment of public discourse, are captured by "double liberal obligations" [7, p. 702]. Power is inevitably between the Scylla of speech freedom and the Charybdis of social equality.

In this regard, it seems constructive to supplement the legal restrictions of public discourse with its transformation. It is necessary to reorient the discourse on key sociopolitical issues from hatred to trust.

\section{Rhetoric of trust: in search of lost foundations}

Confidence rhetoric is a communicative strategy to combat hate speech. Unfortunately, the contemporary public discourse clearly shows the inability of those communicating to express a critical attitude to any phenomenon of reality in a constructive way, that is, without resorting to the rhetoric of hatred in relation to those associated with this phenomenon. An analysis of the discussions on open Internet sites on key value-regulatory issues does not support the rhetoric of trust.

Confidence rhetoric can be defined as a combination of self-expression methods based on trust in the Other, and excluding the discrediting of their normative status on any grounds. The rhetoric of trust does not mean a complete lack of criticism in public discourse. Such an approach would kill it as a tool for constructing social reality. However, the rhetoric of trust requires, firstly, "choose expressions" in value-normative discussions, and, secondly, allows criticizing actions, but not identities. 
There are two options for implementing the reorientation strategy from hate rhetoric to confidence rhetoric: toughening legal sanctions for the use of prohibited hate rhetoric in the public environment and creating an atmosphere of trust in representatives of other social groups. The limitations of the first strategy are discussed above. The state, prohibiting the use of hate rhetoric in public discourse, is always under attack: one or another part of the community has doubts about its legitimacy. If the state does not prohibit using publicly the rhetoric of hatred, discriminated groups question its legitimacy [8]. If, on the contrary, the state imposes strict legal restrictions on the use of hate rhetoric, advocates of freedom of speech doubt its legitimacy, regarding the measures introduced as censorship and unacceptable state interference in the life of citizens.

In this regard, a strategy that focuses on creating an atmosphere of trust in representatives of stigmatized social groups is more promising. However, serious difficulties arise in finding the basis for a trusting relationship. It is impossible to form such a relationship by force. Violence is the ideological foundation of the rhetoric of hatred; it is not compatible with the rhetoric of trust.

Certain prospects as instruments for creating an atmosphere of trust in society have game interactions. For game interactions, differences of race, nationality, religion are secondary in comparison with the tasks of the game itself. The game helps to strengthen horizontal social ties and increase social capital. Moreover, one can speak not only of a quantitative measurement of social capital, but also of a qualitative one [9].

The gaming foundations of culture examined by J. Hasinga [10] allow turning to the game as a social practice in which trust exists and is reproduced in its purest form. If the participants in the game do not trust each other, the game cannot exist, it is destroyed. Therefore, the game is a powerful tool for building trust in each other, as well as in the game itself as a genuine culture.

There is no place for hatred in this game, especially if we consider the cognitive and educational potential of the game. For example, researchers of traditional games $\mathrm{R}$. Pramanik and S. Bhattacharya emphasize their special educational value, comparing them with an educational institution, “... where players learn behavior, friendship and cooperation" [11, p. 99].

However, unfortunately, not every game can get the epithet "real". There are games that provoke players to immoral acts and expressions, produce hatred, not trust. The described phenomenon includes, for example, the so-called "dark play" [12].

Therefore, it is necessary to consider the alternative grounds for building trust in public discourse and forcing out the rhetoric of hatred from it. Two main mechanisms for implementing this strategy can be identified: compromise and consensus.

A compromise, as opposed to a consensus, is not an ideological agreement that does not concern the root of the problem, but a living practice that allows one to really resolve the conflict, even if at first glance it seems completely unsolvable. Consensus is most successfully implemented in states where the rule of law exists both de jure and de facto, and law enforcement also defines the processes of law-making. However, limiting the rhetoric of hatred is a socio-political problem, therefore, to successfully solve it, it is necessary to go beyond purely legal mechanisms. A compromise allows this to be done with the least loss of social capital.

\section{Conclusion}

Restrictions and prohibitions aimed at squeezing out the rhetoric of hatred from public discourse cannot always be adequately perceived by the public. This is due to the peculiarities of the value-regulatory foundations of modern public discourse, which is 
closely related to the concept of human rights. Therefore, to reorient from hatred to trust, it is necessary to look for effective mechanisms in the same value-normative categories.

Legal restrictions and prohibitions on the hate rhetoric use in modern public discourse are clearly not enough. To maintain the proper level of speech freedom, a high level of social trust and the accumulation of social capital are required. Given the scarcity of resources, protecting one's own rights without violating the rights of others can be problematic, therefore compromises and consensus should be found, putting public discourse at least in a conflict of hatred and trust. While the use of hate rhetoric will be perceived as the norm, it is impossible to correctly discuss complex social problems, and, therefore, successfully solve them.

Studying the conflict of hatred and trust unfolding in modern public discourse at different levels of publicity, as well as finding appropriate communication strategies to counter the use of hate rhetoric, is an interesting research task.

The reported study was funded by RFBR according to the research project № 17-03-00094.

\section{References}

1. Y.V. Klyuev, Levels, Models, Elements of the Public Discourse: the Communicative Approach, Vestn. of St.Petersburg University Series 9. Philology. Asian Studies. Journalism, 4(2), 331-338 (2008)

2. P.R. Geren, Public Discourse: Creating the Conditions for Dialogue Concerning the Common Good in a Postmodern Heterogeneous Democracy, Studies in Philosophy and Education, 20(3), 191-199 (2001). Information on: https://doi.org/10.1023/A:1010376511519

3. J. Habermas, The Structural Transformation of the Public Sphere (The MIT Press, Cambridge, 1991)

4. M.N. Sellers, Ideals of Public Discourse. In Republican Legal Theory (Palgrave Macmillan, London, 2003). Information on: https://doi.org/10.1057/9780230513402_8.

5. E. Barendt, What Is the Harm of Hate Speech?, Ethic Theory Moral Prac, 22, 1-15 (2019). Information on: https://doi.org/10.1007/s10677-019-10002-0

6. J. Waldron, The Harm in Hate Speech (Harvard University Press, Cambridge, 2012)

7. R.M. Simpson, Dignity, Harm, and Hate Speech, Law and Philos, 32(6), 701-728 (2013). Information on: https://doi.org/10.1007/s10982-012-9164-z.

8. L.B. Parekh, Limits of Free Speech, Philos, 45(3), 931-935 (2017). Information on: https://doi.org/10.1007/s11406-016-9752-5.

9. B. Gannon, J. Roberts, Social capital: exploring the theory and empirical divide, Empir Econ, 1-21 (2018). Information on: https://doi.org/10.1007/s00181-018-1556-y.

10. J. Huizinga, Homo ludens, A Study of the Play-element in Culture (Ivan Limbakh Publ., St.Petersburg, 2011).

11. R. Pramanik, Sh. Bhattacharya, Play and Indigenous Games of Children: A Cultural Heritage of Western Odisha, India, Knowledge Cultures, 6(2), 96-110 (2018)

12. T.E. Mortensen, J. Linderoth, A. Brown, The Dark Side of Game Play: Controversial Issues in Playful Environments (Routledge, London, 2015) 